\title{
Multiple stimuli induce tyrosine phosphorylation of the Crk-binding sites of paxillin
}

\author{
Michael D. SCHALLER ${ }^{\star 1}$ and Erik M. SCHAEFER $\dagger$ \\ *Department of Cell and Developmental Biology, University of North Carolina, Chapel Hill, NC 27599, U.S.A., and †Signal Transduction and Immunology, QCB, \\ BioSource International, 3 Avenue D, Hopkinton, MA 01748, U.S.A.
}

Paxillin is a focal-adhesion-associated, tyrosine-phosphorylated protein. In cells transformed by the $s r c$, crk or $B C R-A b l$ oncogenes, the phosphotyrosine content of paxillin is elevated. In normal cells paxillin functions in signalling following integrindependent cell adhesion or exposure to a number of stimuli, including growth factors and neuropeptides. These stimuli induce tyrosine phosphorylation of paxillin, regulating the association of Src homology 2 domain-containing signalling molecules with paxillin. There are multiple sites of tyrosine phosphorylation on paxillin. To elucidate the role of paxillin in transducing signals in response to various stimuli, it is essential to identify all of the sites of phosphorylation on paxillin and to define which residues are phosphorylated in response to distinct stimuli. We describe two new sites of tyrosine phosphorylation on paxillin, residues at positions 40 and 88 . Using paxillin variants with phenylalanine substitutions at phosphorylation sites and phospho-specific paxillin antibodies, tyrosine phosphorylation of paxillin in response to distinct stimuli was examined. The results demonstrate that $\mathrm{Tyr}^{31}$ and $\mathrm{Tyr}^{118}$, which are binding sites for Crk, are major sites of tyrosine phosphorylation following cell adhesion or stimulation with platelet-derived growth factor or angiotensin II. Thus multiple stimuli may elicit similar signalling events downstream of paxillin.

Key words: angiotensin, focal adhesions, FAK, integrin, PDGF.

\section{INTRODUCTION}

Tyrosine phosphorylation of cytoskeletal proteins in response to integrin-dependent adhesion is a major mechanism of transducing signals that control many important biological processes, including cell motility and cell survival. Cytoskeletal proteins can also become tyrosine phosphorylated following stimulation with growth factors or reagents that activate G-protein-coupled receptors. Several protein tyrosine kinases may be responsible for phosphorylation of components of the cytoskeleton. The focal adhesion kinase, FAK, is particularly important in integrinmediated signalling, since it prominently co-localizes with the integrins in focal adhesions and has been implicated in controlling several integrin-dependent biological events, including motility and survival [1]. Paxillin is a focal-adhesion-associated, FAKbinding partner that becomes tyrosine phosphorylated in response to multiple stimuli, including cell adhesion [2]. Paxillin is also heavily phosphorylated on tyrosine in cells transformed by a number of oncogenes, suggesting it might also have important functions in the development of cancer [3-5]. Defining how signalling via paxillin is regulated is critical for the elucidation of the molecular mechanisms by which normal cells respond to a range of physiological stimuli, and how these signalling pathways might be subverted in the development of disease.

Paxillin is a $68 \mathrm{kDa}$ protein that may function as an adaptor protein, since it contains multiple docking sites for signalling proteins. The N-terminal half of paxillin contains five LeuAsp (LD) motifs, which are short peptide sequences that mediate interactions with other proteins [6]. The LD motifs serve as binding sites for FAK, cell adhesion kinase $\beta$ / proline-rich kinase2 ('CAK $\beta /$ Pyk2'), vinculin, the E6 oncoprotein of papilloma- virus and p95 paxillin-kinase linker ('PKL') [6,7]. There is a proline-rich region near the $\mathrm{N}$-terminus of paxillin that can function as a binding site for the Src homology ( $\mathrm{SH}) 3$ domain of Src [8]. The N-terminal domain of paxillin also contains a number of tyrosine residues that are candidate sites of phosphorylation and docking sites for $\mathrm{SH} 2$ domain-containing proteins [5,9-11]. The C-terminal half of paxillin contains four LIM (an acronym of the three gene products lin-11, isl-1 and mec-3) domains [5,9]. LIM domains mediate protein-protein interactions and the third LIM domain contains the major focaladhesion-targeting sequence of paxillin $[12,13]$. The presumed binding partner responsible for localizing paxillin in focal adhesions remains to be identified.

The function of paxillin has not been completely elucidated, but recent work has suggested it controls spreading and motility. Inhibition of FAK signalling using a dominant-negative strategy impairs cell spreading on fibronectin and reduced tyrosine phosphorylation of paxillin was correlated with this effect $[14,15]$. Tyrosine phosphorylation of paxillin has been implicated in regulating cell motility in certain scenarios, although the effect upon motility is controversial. In one report [16], tyrosine phosphorylation of paxillin appears to promote motility, whereas another report [17] suggests tyrosine phosphorylation of paxillin retards cell motility. Further evidence for a role for paxillin in controlling cell spreading and motility comes from the analysis of chimaeric integrins. The $\alpha_{4}$ integrin subunit binds tightly to paxillin, both in vitro and in vivo [18]. Expression of a chimaeric fibrinogen receptor, with the cytoplasmic domains of the $\alpha_{4}$ and $\beta_{1}$ integrin subunits substituted for the natural cytoplasmic domains, promotes adhesion of Chinese-hamster ovary cells to fibrinogen. However, this chimaeric receptor does not promote

Abbreviations used: SH, Src homology; PDGF, platelet-derived growth factor; FAK, focal adhesion kinase; LD motif, Leu-Asp motif; LIM, an acronym of the three gene products lin-11, isl-1 and mec-3; CE, chicken embryo; DMEM, Dulbecco's modified Eagle's medium; FCS, fetal calf serum; TGF, transforming growth factor; Ang II, angiotensin II; RMEM, Richter's modified Eagle's medium.

1 To whom correspondence should be addressed (e-mail crispy4@med.unc.edu). 
spreading on fibrinogen, and the cells exhibit enhanced motility on fibrinogen relative to cells expressing the wild-type fibrinogen receptor. A number of lines of evidence demonstrate that paxillin binding to the $\alpha_{4}$ subunit is required to inhibit spreading and enhance motility of these cells on fibrinogen [18]. In some situations, paxillin may also play a role in adhesion, since expression of paxillin mutants containing substitutions at sites of serine and threonine phosphorylation within the LIM domains alters cell adhesion to fibronectin [19].

Paxillin becomes tyrosine phosphorylated in response to a number of stimuli, including cell adhesion and stimulation by some G-protein-coupled receptors [20]. In addition, levels of phosphotyrosine are elevated in cells transformed by several oncogenes, including src, $c r k$ and $B C R-A b l$ [3-5]. Tyrosine phosphorylation of paxillin plays an important role in regulating the transmission of downstream signals, since expression of tyrosine-to-phenylalanine substitution mutants of paxillin induces cellular phenotypes that are different from those induced by expression of wild-type paxillin [16,17]. $\mathrm{Tyr}^{31}$ and $\mathrm{Tyr}^{118}$ have been identified as sites of phosphorylation in paxillin and serve as binding sites for Crk $[10,11]$. Thus signalling downstream of paxillin is envisioned to involve the recruitment of Crk, and Crkassociated enzymes like C3G and DOCK180, into a complex with paxillin. However, there also appears to be additional sites of tyrosine phosphorylation on paxillin that may mediate the binding of other $\mathrm{SH} 2$ domain-containing proteins that associate with paxillin, e.g. C-terminal src kinase ('Csk') [11,21,22]. In order to fully elucidate the role of paxillin in signalling, it is essential to identify all of the sites of phosphorylation of paxillin, and to determine which sites become phosphorylated in response to distinct stimuli. We now report that $\mathrm{Tyr}^{40}$ and $\mathrm{Tyr}^{88}$ are additional sites of paxillin phosphorylation. Using a combination of tyrosine-to-phenylalanine substitution mutants and phosphospecific paxillin antibodies, tyrosine phosphorylation of paxillin in response to different stimuli was examined. $\mathrm{Tyr}^{31}$ and $\mathrm{Tyr}^{118}$ were found to be major sites of tyrosine phosphorylation following the adhesion of fibroblasts or smooth-muscle cells to fibronectin. Interestingly, $\mathrm{Tyr}^{88}$ was required for a shift in the mobility of paxillin on SDS/polyacrylamide gels. In addition, $\mathrm{Tyr}^{31}$ and $\mathrm{Tyr}^{88}$ were also shown to be sites of phosphorylation induced by Ang II stimulation of GN4 cells and platelet-derived growth factor (PDGF) stimulation of A7r5 cells. Thus multiple stimuli appear to trigger tyrosine phosphorylation of paxillin at similar residues to create Crk-binding sites.

\section{EXPERIMENTAL}

\section{Cells}

Chicken embryo (CE) cells were isolated and maintained in Dulbecco's modified Eagle's medium (DMEM) containing 5\% fetal calf serum (FCS) and 1\% chick serum as previously described [23]. Paxillin and Src were expressed in CE cells using the RCAS and pRL replication-competent avian retroviral vectors [23,24]. Plasmid DNA was introduced into CE cells by transfection $[23,24]$. The rat A7r5 smooth-muscle-cell line was obtained from the A.T.C.C. and was maintained in DMEM supplemented with $10 \%$ FCS. Cells were serum-starved for $48 \mathrm{~h}$ in DMEM supplemented with $0.1 \%$ FCS prior to stimulation with $2 \mathrm{ng} / \mathrm{ml}$ PDGF (Sigma, St. Louis, MO, U.S.A.) for $10 \mathrm{~min}$ at $37^{\circ} \mathrm{C}$. The rat GN4 liver cell line (provided by Dr Shelton Earp, Comprehensive Cancer Center University of North Carolina at Chapel Hill, Chapel Hill, NC, U.S.A.) was maintained in Richter's modified Eagle's medium (RMEM) supplemented with $10 \%$ FCS. GN4 cells were serum-starved in RMEM for $48 \mathrm{~h}$ prior to stimulation with $1 \mu \mathrm{M}$ angiotensin II (Ang II;
Sigma) for $90 \mathrm{~s}$ at $37^{\circ} \mathrm{C}$. To study cell adhesion-dependent tyrosine phosphorylation, cells were removed from tissue-culture dishes by trypsinization and the trypsin was inactivated by washing twice with soybean trypsin inhibitor (Sigma). Cells were resuspended in serum-free DMEM, held in suspension at $37^{\circ} \mathrm{C}$ and plated on to Petri dishes coated with fibronectin as previously described $[25,26]$.

\section{Molecular biology}

A fragment of the paxillin cDNA extending from the $5^{\prime}$ end to the $\mathrm{SacI}$ site at nucleotide 705 was subcloned into the pAlter vector (Promega, Madison, WI, U.S.A.) for mutagenesis. Oligonucleotide-directed mutagenesis was performed to introduce substitutions into the paxillin cDNA. Mutant clones were detected by nucleotide sequencing. For expression in Escherichia coli the paxillin inserts from the pAlter plasmids were amplified by PCR using a $5^{\prime}$ primer that removed the initiation codon and engineered a Bam $\mathrm{HI}$ restriction site. The Bam $\mathrm{HI}$ site was designed so that the paxillin sequences would be in-frame with the start codon and histidine tag found in the pRSET vector. The $3^{\prime}$ primer annealed downstream of the paxillin insert and the BamHI site of the multiple cloning site of pAlter. The amplification product was cleaved with $B a m \mathrm{HI}$ and inserted into the BamHI site of pRSET B (Invitrogen, San Diego, CA, U.S.A.). For expression in avian cells, the fragment of the mutant paxillin cDNAs extending from the EcoRI site (at the $5^{\prime}$ end of the cDNA) to the SacI site (at nucleotide 705) were excised from pAlter and substituted for the corresponding wild-type sequence in the plasmid pBSctag/paxillin [24]. The $3^{\prime}$ end of the paxillin coding sequences in this plasmid is fused in-frame with sequences encoding the KT3 epitope tag. Each of the pRSET/paxillin and $\mathrm{pBSctag} /$ paxillin constructs were subjected to nucleotide sequencing analysis to verify that the targeted mutations were present, and that no unintended mutations were introduced into the constructs. Nucleotide sequencing was performed using a Sequenase kit (Amersham Pharmacia Biotech, Piscataway, NJ, U.S.A.). The mutated, epitope-tagged inserts from the pBSctag/ paxillin constructs were subcloned into the RCAS A avian, replication competent, retroviral vector.

\section{Phosphopeptide analysis}

pRSET derivatives were introduced into E. coli JM109. Expression was induced by addition of isopropyl $\beta$-D-thiogalactoside and infection with recombinant M13 bacteriophage engineered to express the $\mathrm{T} 7$ polymerase (Invitrogen). Bacterial lysates were incubated with a commercially available paxillin monoclonal antibody (Transduction Laboratories, San Diego, CA, U.S.A.), and the recombinant paxillin fragments phosphorylated by $\mathrm{Src}$ in an in vitro kinase assay. Src was immunoprecipitated from $\mathrm{CE}$ cell lysates expressing the activated mutant $\mathrm{Src}^{527 \mathrm{~F}}$ using the monoclonal antibody EC10 (a gift from Dr Sally Parsons, Department of Microbiology University of Virginia, Charlottesville, VA, U.S.A.). Immune complexes containing the recombinant fragments of paxillin were mixed with Src-containing immune complexes and co-precipitated using Protein A-Sepharose coated with anti-mouse IgG antibodies. The resulting immunoprecipitates were incubated in an in vitro kinase assay as described previously [11]. As a control, full-length wild-type paxillin, endogenously expressed in CE cells, was immunoprecipitated and analysed in parallel. Samples were analysed by SDS/PAGE and transferred on to nitrocellulose membranes. Radiolabelled paxillin was visualized by autoradiography. The bands were excised, trypsinized and phosphopeptide analysis was performed as described previously [11]. A synthetic 
peptide mimicking the tryptic peptide of paxillin containing $\mathrm{Tyr}^{88}$ (YGHQQPQSQSPIYSSSAK; Biosource International, Camarillo, CA, U.S.A.) was phosphorylated by $\mathrm{Src}$ in an in vitro kinase assay and purified by high voltage electrophoresis as described previously [11]. The phosphorylated peptide was then analysed by high voltage electrophoresis and chromatography [11].

\section{Protein analysis}

Cells were lysed on ice in RIPA buffer [50 mM Tris ( $\mathrm{pH} 7.3) /$ $150 \mathrm{mM} \mathrm{NaCl} / 1 \%$ Triton X-100/0.5\% deoxycholate] containing protease and phosphatase inhibitors [24]. Exogenously expressed paxillin was immunoprecipitated using the KT3 monoclonal antibody. Endogenous paxillin was immunoprecipitated using the 8605 polyclonal antiserum [24]. Paxillin was immunoprecipitated, the samples eluted in Laemmli sample buffer and analysed by Western blotting as described previously [24,27]. Membranes were blocked with $10 \mathrm{mM}$ Tris $(\mathrm{pH} 7.5) / 150 \mathrm{mM}$ $\mathrm{NaCl} / 0.1 \%$ Tween 20 containing $5 \%(\mathrm{w} / \mathrm{v})$ powdered milk (for blots to detect proteins) or $5 \%(\mathrm{w} / \mathrm{v}) \mathrm{BSA}$ (for blots to detect phosphotyrosine and blots using phospho-specific antibodies). KT3 and a polyclonal paxillin antiserum were used to detect paxillin [24]. RC20 (Transduction Laboratories) was used for the detection of phosphotyrosine. Phospho-specific paxillin antibodies that recognize paxillin when phosphorylated on $\mathrm{Tyr}^{31}$ (PY31) or $\mathrm{Tyr}^{118}$ (PY118) (Biosource International), were used for Western blotting in this analysis. These affinity purified (using both negative and positive affinity purification methods) rabbit polyclonal antibodies have been shown to be highly selective for the targeted phosphorylation site, as demonstrated by peptide competition studies. The phospho-specific paxillin antibodies were used at approx. $0.3 \mu \mathrm{g} / \mathrm{ml}$. Horseradish peroxidase-conjugated Protein A (1:1000; Amersham Pharmacia Biotech) was used as a secondary reagent to detect the phosphospecific antibodies. Enhanced chemiluminescence was used as the detection system following Western blotting (Amersham Pharmacia Biotech).

\section{RESULTS}

\section{Identification of additional sites of tyrosine phosphorylation in paxillin}

The tryptic phosphopeptide map of paxillin phosphorylated in vitro by Src contains three major phosphopeptides: peptide a, which contains $\operatorname{Tyr}^{31}$ and $\mathrm{Tyr}^{40}$, peptide $\mathbf{b}$, which contains $\mathrm{Tyr}^{118}$ and peptide c, which has not been characterized [11]. To identify the site of phosphorylation in peptide $\mathbf{c}$, the radiolabelled tryptic phosphopeptide was isolated from a TLC plate and analysed by automated Edman degradation sequencing [11]. The radioactivity incorporated into peptide $\mathbf{c}$ was released in sequencing cycle 13 (results not shown). Examination of the predicted amino acid sequence of paxillin revealed only one tyrosine residue that was 13 amino acids downstream of a tryptic cleavage site, $\mathrm{Tyr}^{88}$. This result suggests that phosphopeptide $\mathbf{c}$ is phosphorylated on $\mathrm{Tyr}^{88}$ of paxillin.

To further analyse tyrosine phosphorylation of paxillin, phenylalanine substitutions were made for each of four candidate tyrosine phosphorylation sites of paxillin $\left(\mathrm{Tyr}^{31}, \mathrm{Tyr}^{40}, \mathrm{Tyr}^{88}\right.$ and $\mathrm{Tyr}^{118}$ ), either alone or in combination, using oligonucleotidedirected mutagenesis. To study tyrosine phosphorylation of paxillin mutants in vitro, the $\mathrm{NH}_{2}$-terminal fragment of each paxillin variant, containing the first 238 residues, was expressed as a recombinant protein in E. coli using the pRSET expression system. Although the yield of protein was very low, sufficient material was obtained to perform the analysis. The recombinant proteins were captured from bacterial lysates using a monoclonal antibody and mixed immune complexes containing the recombinant paxillin and Src (isolated from CE cell lysates) proteins were formed. The resulting immune complexes were incubated in an in vitro kinase assay under conditions that were previously shown to phosphorylate paxillin on the same tyrosine residues that are phosphorylated in vivo [11]. All of the mutants containing a single phenylalanine-for-tyrosine substitution (paxillin $^{\mathrm{Y} 31 \mathrm{~F}}$, paxillin $^{\mathrm{Y} 40 \mathrm{~F}}$, paxillin ${ }^{\mathrm{Y} 88 \mathrm{~F}}$, paxillin ${ }^{\mathrm{Y} 118 \mathrm{~F}}$ ) were phosphorylated by Src in vitro (Figure 1, lanes 3-6). Src also phosphorylated paxillin $^{\mathrm{Y} 31 \mathrm{~F} / \mathrm{Y} 40 \mathrm{~F}}$, which contains substitutions of phenylalanine for $\mathrm{Tyr}^{31}$ and $\mathrm{Tyr}^{40}$ and paxillin ${ }^{\mathrm{Y} 31 \mathrm{~F} / \mathrm{Y} 118 \mathrm{~F}}$, which contains substitutions of phenylalanine for $\mathrm{Tyr}^{31}$ and $\mathrm{Tyr}^{118}$ (Figure 1, lanes 7 and 8). In contrast, Src did not phosphorylate paxillin ${ }^{4 \mathrm{~F}}$, which contains phenylalanine substitutions for $\mathrm{Tyr}^{31}, \mathrm{Tyr}^{40}, \mathrm{Tyr}^{88}$ and Tyr $^{118}$ (Figure 1, lane 9). This result suggests that tyrosine phosphorylation of the $\mathrm{NH}_{2}$-terminal domain of paxillin by $\mathrm{Src}$ is restricted to these four residues and that tyrosine phosphorylation of another potential phosphorylation site, $\operatorname{Tyr}^{181}[5,9]$, is negligible under the conditions of the assay.

The paxillin mutants were further analysed by phosphopeptide mapping. Initially, the phosphopeptide maps of paxillin isolated from CE cells and the recombinant fragment of wild-type paxillin were compared and found to be identical (results not shown). The map of paxillin ${ }^{\mathrm{Y} 88 \mathrm{~F}}$ contained the two major peptides a and b, but was missing peptide c (Figure 2B). This result indicates that $\mathrm{Tyr}^{88}$ is a site of phosphorylation by Src in vitro. To further substantiate this conclusion, a synthetic peptide identical in sequence to the predicted tryptic peptide of paxillin containing $\mathrm{Tyr}^{88}$ was analysed. The peptide was phosphorylated by Src in vitro and analysed by high voltage electrophoresis and chromatography. The major spot in the phosphopeptide map exhibited electrophoretic and chromatographic properties similar to peptide c (Figure 2C, arrow). To determine if the phosphorylated synthetic peptide co-migrated with peptide c, the samples in Figures 2(A) and (C) were mixed and analysed. The resulting map exhibited the same three major phosphopeptides found in panel A (Figure 2D). Further, in the mixture the intensity of peptide $\mathbf{c}$ was elevated compared with the intensity of peptide $\mathbf{c}$ in Figure 2(A). These observations demonstrate that the synthetic peptide co-migrated with peptide c. These data support the conclusion that $\mathrm{Tyr}^{88}$ of paxillin is a site of phosphorylation for Src in vitro.

Phosphopeptide maps of the other paxillin mutants were also examined. The map of paxillin ${ }^{\mathrm{Y} 118 \mathrm{~F}}$ contained peptides a and $\mathbf{c}$, but was missing peptide b (results not shown). This result is consistent with the conclusion that peptide $\mathbf{b}$ is phosphorylated on $\mathrm{Tyr}^{118}$ of paxillin [11]. The phosphopeptide map of paxillin ${ }^{\mathrm{Y} 31 \mathrm{~F}}$ was identical with that of wild-type paxillin (Figures $2 \mathrm{~A}$ and $2 \mathrm{E})$. This result was not completely anticipated since $\mathrm{Tyr}^{31}$ was previously identified as a site of phosphorylation [11]. However, there was also evidence that this peptide might contain a second phosphorylated tyrosine residue, $\mathrm{Tyr}^{40}$. The phosphopeptide map of paxillin ${ }^{\mathrm{Y} 40 \mathrm{~F}}$ was also identical to the map of wild-type paxillin (Figures $2 \mathrm{~A}$ and $2 \mathrm{~F}$ ). However, mutation of both $\mathrm{Try}^{31}$ and $\mathrm{Tyr}^{41}$ (in paxillin ${ }^{\mathrm{Y} 31 \mathrm{~F} / \mathrm{Y} 40 \mathrm{~F}}$ ) resulted in the loss of peptide a from the phosphopeptide map (Figure 2G). These results demonstrate that this peptide indeed contains two tyrosine residues that can be phosphorylated by Src in vitro.

\section{Tyrosine phosphorylation of paxillin mutants in vivo}

In order to examine tyrosine phosphorylation of the paxillin mutants in vivo each was engineered into full-length, epitope- 


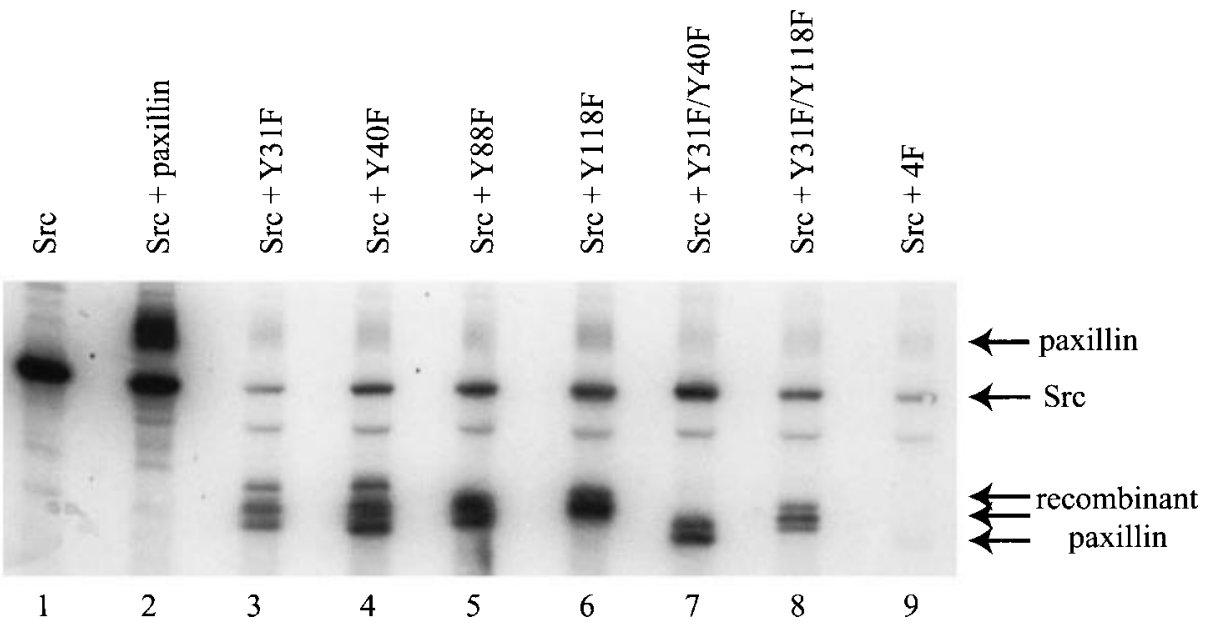

Figure 1 Tyrosine phosphorylation of recombinant paxillin fragments in vitro by Src

Src immune complexes were incubated in an in vitro protein kinase assay either alone (lane 1) or after mixing with immune complexes containing paxillin substrates (lanes 2-9). Full-length avian paxillin was immunoprecipitated from a CE cell lysate (lane 2). Recombinant fragments of paxillin mutants, including Y31F (lane 3), Y40F (lane 4), Y88F (lane 5), Y118F (lane 6), Y31F/Y40F (lane 7), Y31F/Y118F (lane 8) and 4F (lane 9), were expressed in E. coli and immunoprecipitated from E. coli lysates. Kinase reactions were terminated by addition of Laemmli sample buffer and the samples analysed by SDS/PAGE and autoradiography. The positions of the full-length avian paxillin, Src and the recombinant paxillin fragments are indicated.

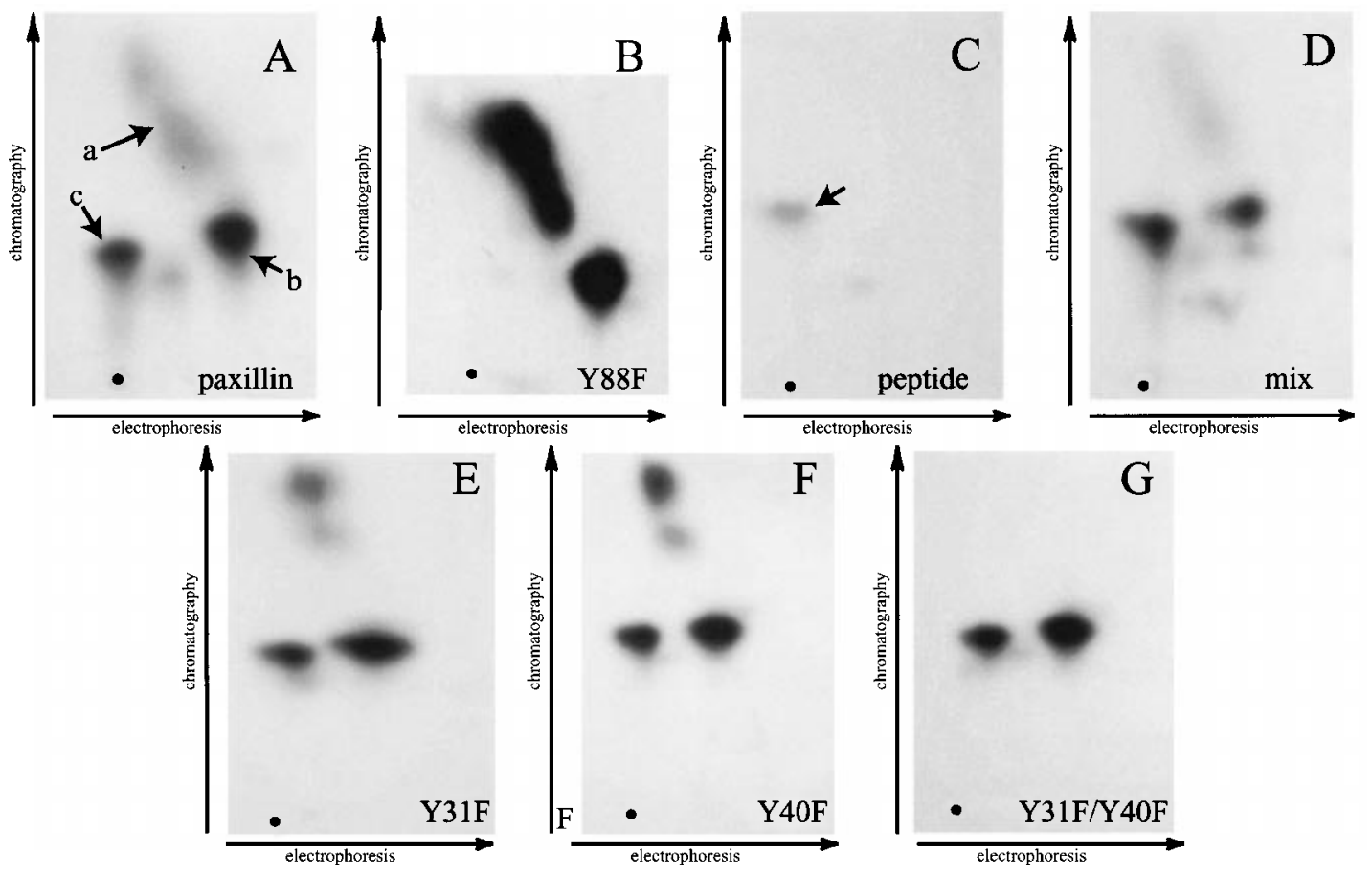

Figure 2 Phosphopeptide mapping of paxillin

Full-length avian paxillin $(\mathbf{A})$ and the recombinant fragments of paxillin mutants $\mathrm{Y} 88 \mathrm{~F}(\mathbf{B}), \mathrm{Y} 31 \mathrm{~F}(\mathbf{E}), \mathrm{Y} 40 \mathrm{~F}(\mathbf{F})$ and $\mathrm{Y} 31 \mathrm{~F} / \mathrm{Y} 40 \mathrm{~F}(\mathbf{G})$ were radiolabelled by Src in vitro as in Figure 1. The proteins were transferred on to nitrocellulose, trypsinized and analysed by high-voltage electrophoresis and chromatography as previously described [11]. Phosphopeptides $\mathbf{a}, \mathbf{b}$ and $\mathbf{c}$ are identified by arrows in (A). A synthetic peptide mimicking the predicted tryptic peptide containing Tyr ${ }^{88}$ of paxillin was labelled by Src in vitro and purified by high-voltage electrophoresis on a TLC plate as described in [11]. The peptide was then analysed by-high voltage electrophoresis and chromatography (C). A mixture of the samples from (A) and (C) were analysed in (D). The directions of electrophoresis and chromatography are indicated. The solid circle indicates the origin on the TLC plate.

tagged paxillin and subcloned into the RCAS A replicationcompetent retroviral vector. The mutants were expressed in $\mathrm{CE}$ cells. Exogenously expressed paxillin was immunoprecipitated using an antibody recognizing the KT3 epitope tag and tyrosine phosphorylation was examined by Western blotting. Epitopetagged wild-type paxillin was tyrosine phosphorylated (Figures 

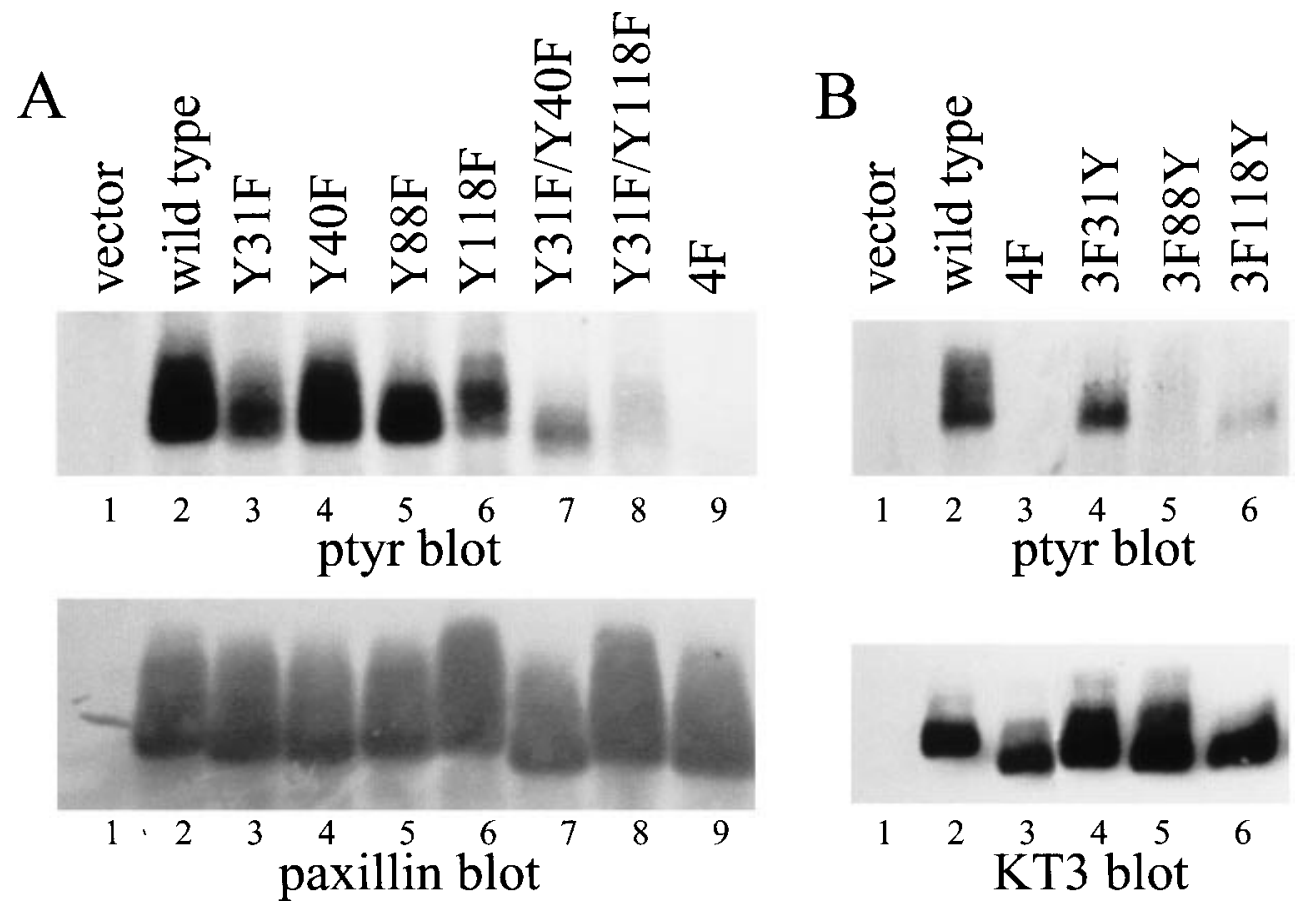

\section{Figure 3 Expression and tyrosine phosphorylation of paxillin mutants in CE cells}

Epitope-tagged paxillin constructs were expressed in CE cells using the RCAS A vector. (A) Cells transfected with the empty vector (lane 1) or with RCAS A containing wild-type paxillin (lane 2), paxillin ${ }^{\mathrm{Y} 1 \mathrm{~F}}$ (lane 3), paxillin ${ }^{\mathrm{Y} 0 \mathrm{~F}}$ (lane 4), paxillin ${ }^{\mathrm{Y} 8 \mathrm{~F}}$ (lane 5), paxillin ${ }^{\mathrm{Y} 118 \mathrm{~F}}$ (lane 6), paxillin ${ }^{\mathrm{Y} 1 \mathrm{~F} / \mathrm{Y}_{40 \mathrm{~F}}}$ (lane 7), paxillin ${ }^{\mathrm{Y} 31 \mathrm{~F} / \mathrm{Y} 118 \mathrm{~F}}$ (lane 8 ) or paxillin ${ }^{4 \mathrm{~F}}$ (lane 9) were lysed. Exogenous paxillin was immunoprecipitated with KT3, which recognizes the epitope tag, and the samples were analysed by Western blotting for phosphotyrosine (ptyr; upper panel). The blot was stripped and reprobed with a paxillin polyclonal antiserum as a loading control (lower panel). (B) Cells transfected with the empty vector (lane 1) or with RCAS A containing wild-type paxillin (lane 2), paxillin ${ }^{4 F}$ (lane 3), paxillin ${ }^{3 F 31 Y}$ (lane 4), paxillin ${ }^{3 F 88 Y}$ (lane 5) or paxillin ${ }^{3 F 118 Y}$ (lane 6) were lysed and analysed as in (A). The phosphotyrosine Western-blot (ptyr; upper panel) was stripped and reprobed with KT3 (lower panel) as a loading control.

$3 \mathrm{~A}$ and $3 \mathrm{~B}$, lanes 2) [24]. In contrast, paxillin ${ }^{4 \mathrm{~F}}$ contained no detectable tyrosine phosphorylation (Figures 3A, lane 9 and 3B, lane 3 ). Thus in cells growing in tissue culture, tyrosine phosphorylation of paxillin was restricted to these four tyrosine residues. Tyr ${ }^{31}$ was a major site of phosphorylation on paxillin since paxillin $^{31 \mathrm{~F}}$ exhibited a very dramatic reduction in the amount of phosphotyrosine relative to wild-type paxillin (Figure $3 \mathrm{~A}$, lane 3 ). In addition, paxillin ${ }^{3 \mathrm{~F} 31 \mathrm{Y}}$, which has phenylalanine substitutions at $\mathrm{Tyr}^{40}, \mathrm{Tyr}^{88}$ and $\mathrm{Tyr}^{118}$, still exhibits substantial tyrosine phosphorylation (Figure 3B, lane 4). However, there are clearly other tyrosine-phosphorylated residues, since paxillin ${ }^{31 \mathrm{~F}}$ is not devoid of phosphotyrosine and paxillin ${ }^{3 \mathrm{~F} 31 \mathrm{Y}}$ does not exhibit wild-type levels of phosphotyrosine (Figures 3A, lane 3 and $3 \mathrm{~B}$, lane 4$)$. $\mathrm{Tyr}^{118}$ was a second site of phosphorylation as shown by the reduction in tyrosine phosphorylation of paxillin $^{\mathrm{Y} 118 \mathrm{~F}}$ relative to wild-type paxillin (Figure 3A, lane 6). In addition, paxillin ${ }^{3 \mathrm{~F} 118 \mathrm{Y}}$, which has substitutions for $\mathrm{Tyr}^{31}, \mathrm{Tyr}^{40}$ and $\mathrm{Tyr}^{88}$, contains phosphotyrosine (Figure 3B, lane 6). $\mathrm{Tyr}^{31}$ and $\mathrm{Tyr}^{118}$ appeared to be the predominant sites of phosphorylation in vivo since paxillin ${ }^{\mathrm{Y} 31 \mathrm{~F} / \mathrm{Y} 118 \mathrm{~F}}$ exhibited very dramatically reduced levels of phosphotyrosine relative to wildtype paxillin (Figure 3A, lane 8). Nevertheless, there are other tyrosine residues that were phosphorylated, since paxillin $^{\mathrm{Y} 31 \mathrm{~F} / \mathrm{Y} 118 \mathrm{~F}}$ was still not devoid of phosphotyrosine. In contrast, there was little difference in the phosphotyrosine levels of wild-type paxillin and paxillin ${ }^{\mathrm{Y} 40 \mathrm{~F}}$, suggesting that this may be a minor site of phosphorylation in CE cells (Figure 3A, lane 4). Paxillin ${ }^{\mathrm{Y} 88 \mathrm{~F}}$ was also prominently phosphorylated on tyrosine (Figure 3A, lane 5). However, in contrast with tyrosine phosphorylated wild-type paxillin, which exhibited a heterogeneous electrophoretic mobility (Figure 3A, lane 2), tyrosine phosphorylated paxillin ${ }^{\mathrm{Y} 88 \mathrm{~F}}$ migrated as a tight band on the gel (Figure 3A, lane 5). Thus phosphorylation at $\mathrm{Tyr}^{88}$ may contribute to the retarded electrophoretic mobility characteristic of tyrosine-phosphorylated paxillin. There is very little tyrosine phosphorylation detected on paxillin ${ }^{3 \mathrm{~F} 88 \mathrm{Y}}$, which has substitutions for $\mathrm{Tyr}^{31}, \mathrm{Tyr}^{40}$ and $\mathrm{Tyr}^{118}$, suggesting that $\mathrm{Tyr}^{88}$ may be a minor site of phosphorylation (Figure 3B, lane 5). The phosphotyrosine Western blots were stripped and reprobed with a paxillin polyclonal antiserum (Figure 3A, bottom panel) or with KT3 (Figure 3B, bottom panel) to verify that the observed differences in tyrosine phosphorylation were not due to differential recovery of protein.

\section{Tyrosine phosphorylation of paxillin mutants following adhesion to fibronectin}

A major stimulus controlling tyrosine phosphorylation of paxillin is integrin-dependent cell adhesion. To explore the regulation of tyrosine phosphorylation of the mutants, cells were trypsinized, held in suspension and plated on to fibronectin-coated dishes. Cells were lysed after incubation at $37^{\circ} \mathrm{C}$ for $60 \mathrm{~min}$. The exogenously expressed paxillin was immunoprecipitated using KT3 and analysed for phosphotyrosine by Western blotting. As previously described, tyrosine phosphorylation of wild-type epitope-tagged paxillin was regulated by cell adhesion [24] (Figure 4, lanes 1-3). Tyrosine phosphorylation disappeared when cells were taken into suspension and then returned upon plating the 

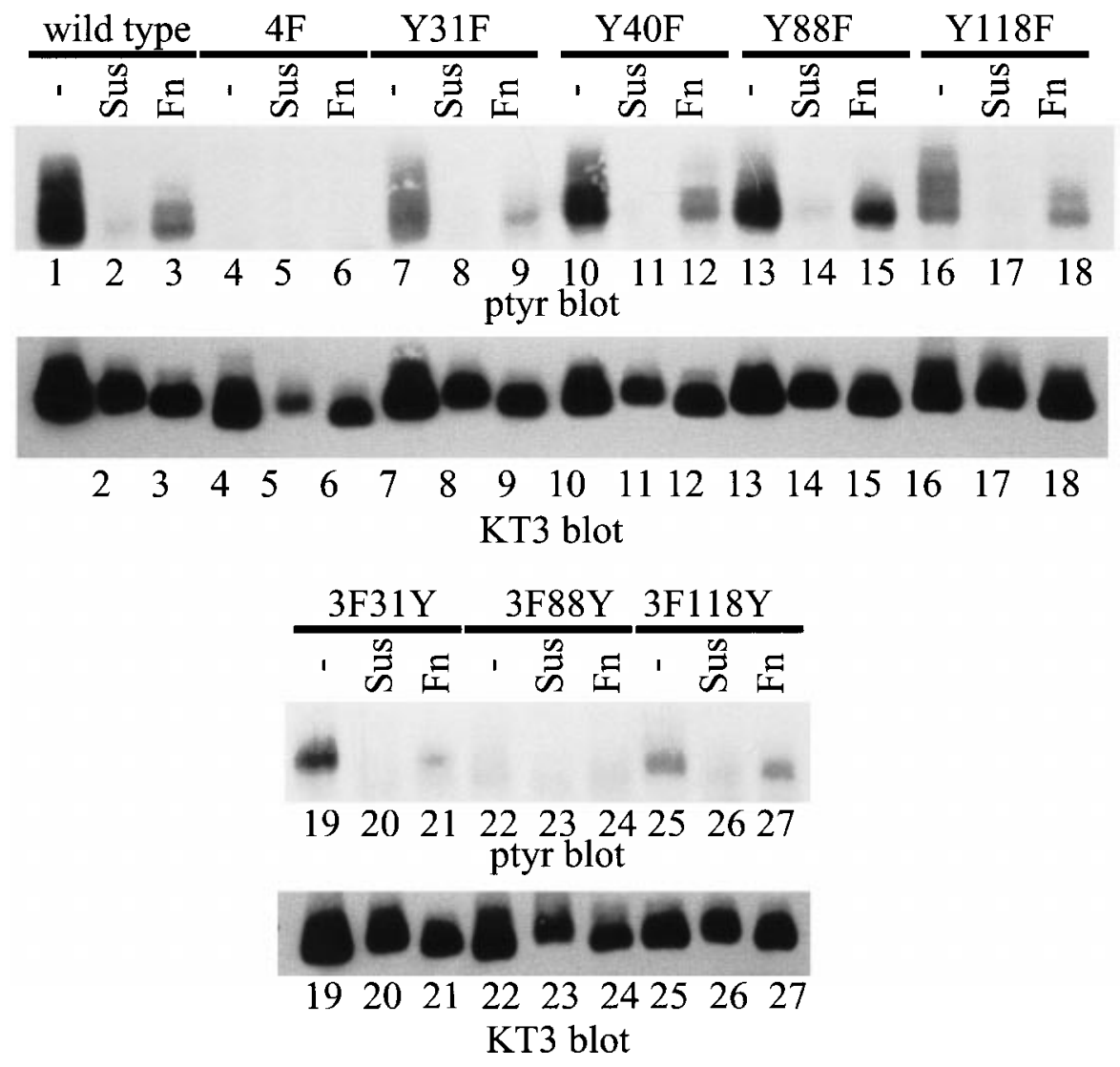

\section{Figure 4 Tyrosine phosphorylation of paxillin mutants in response to cell adhesion}

Cells expressing wild-type paxillin (lanes 1-3), paxillin ${ }^{4 \mathrm{~F}}$ (lanes 4-6), paxillin ${ }^{\mathrm{Y} 31 \mathrm{~F}}$ (lanes 7-9), paxillin ${ }^{\text {Y40F }}$ (lanes 10-12), paxillin ${ }^{\text {Y88F }}$ (lanes 13-15), paxillin ${ }^{\text {Y118F }}$ (lanes 16-18), paxillin ${ }^{3 F 31 Y}$ (lanes 19-21), paxillin ${ }^{3 F 88 Y}$ (lanes 22-24) or paxillin ${ }^{3 F 118 Y}$ (lanes 25-27) were held in suspension (lanes 2, 5, 8, 11, 14, 17, 20, 23 and 26) or plated on to fibronectin for $1 \mathrm{~h}$ (lanes $3,6,9,12,15$, 18, 21, 24 and 27) prior to lysis. Cells growing in culture were lysed as controls (lanes 1, 4, 7, 10, 13, 16, 19, 22 and 25). Exogenously expressed paxillin was immunoprecipitated using KT3 and Western-blotted with a phosphotyrosine antibody (ptyr; top panels). The blots were stripped and reprobed with KT3 as a loading control (bottom panels).

cells on fibronectin. Paxillin ${ }^{4 \mathrm{~F}}$ was devoid of phosphotyrosine in cells growing in culture and did not become tyrosine phosphorylated upon adhesion to fibronectin (Figure 4, lanes 4-6). Thus cell adhesion-dependent tyrosine phosphorylation appears to be restricted to the four sites of phosphorylation identified in the N-terminal half of paxillin $\left(\mathrm{Tyr}^{31}, \mathrm{Tyr}^{40}\right.$, $\mathrm{Tyr}^{88}$ and $\mathrm{Tyr}^{118}$ ). A major site of cell adhesion-dependent tyrosine phosphorylation of paxillin in CE cells was $\mathrm{Tyr}^{31}$. Paxillin ${ }^{\mathrm{Y} 31 \mathrm{~F}}$ exhibited a dramatic decrease in the level of tyrosine phosphorylation following cell adhesion when compared with wild-type paxillin (Figure 4, lanes 7-9). Paxillin ${ }^{\mathrm{Y} 118 \mathrm{~F}}$ also exhibited a decrease in tyrosine phosphorylation following adhesion to fibronectin, suggesting that $\mathrm{Tyr}^{118}$ also becomes phosphorylated in response to cell adhesion (Figure 4, lanes 16-18). In addition, both paxillin ${ }^{3 \mathrm{~F} 31 \mathrm{Y}}$ and paxillin ${ }^{3 \mathrm{~F} 118 \mathrm{Y}}$ became tyrosine phosphorylated following adhesion to fibronectin (Figure 4, lanes 19-21 and 25-27, respectively). Paxillin ${ }^{\mathrm{Y} 40 \mathrm{~F}}$ showed little reduction in tyrosine phosphorylation following adhesion relative to levels seen in the wild-type protein (Figure 4, lanes 10-11). Again, this argues that $\mathrm{Tyr}^{40}$ is, at best, a minor site of phosphorylation following adhesion of CE cells to fibronectin. Paxillin ${ }^{\mathrm{Y} 88 \mathrm{~F}}$ also became tyrosine phosphorylated after plating on fibronectin (Figure 4, lanes 13-15). Although the intensity of the signal appeared equal to, or even greater than, that of wild-type paxillin, it was striking that only a single species of paxillin ${ }^{\mathrm{Y} 88 \mathrm{~F}}$ was detected (Figure 4, lane 15). This contrasts with the multiple isomers of tyrosine-phosphorylated paxillin, appearing as a broad heterogeneous band on the blot, found with each of the other constructs. This observation suggests that $\mathrm{Tyr}^{88}$ is required for a change in the electrophoretic mobility of paxillin following cell adhesion.

\section{Characterization of phospho-specific paxillin antibodies}

The substitution mutants described here have been utilized to characterize two phosphorylation site-specific antibodies to paxillin. PY31 is directed against tyrosine-phosphorylated residue at position 31 and PY118 is directed against tyrosinephosphorylated residue at position 118 . For this analysis, paxillin mutants were expressed in CE cells and the cells were treated with $50 \mathrm{mM}$ pervanadate for $30 \mathrm{~min}$ to stimulate maximum tyrosine phosphorylation. The mutants were immunoprecipitated from cell lysates using KT3 and the proteins analysed by Western blotting. For comparison, endogenous paxillin was immunoprecipitated from lysates of $\mathrm{CE}$ cells that were not pervanadate treated and analysed in parallel. Note that the amount of endogenous paxillin analysed corresponds to the amount immunoprecipitated from $500 \mu \mathrm{g}$ of lysate, and the amount of exogenous paxillin corresponds to the amount immunoprecipitated from $20 \mu \mathrm{g}$ of lysate from pervanadate-treated cells. 
A

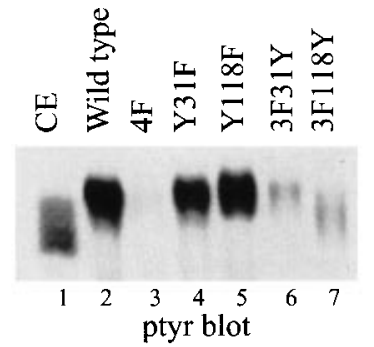

B

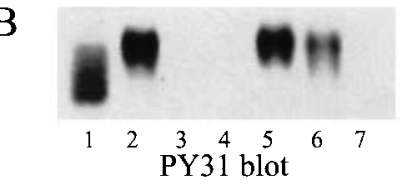

$\mathrm{C}$

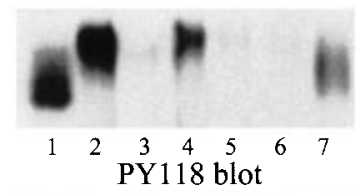

$\mathrm{D}$

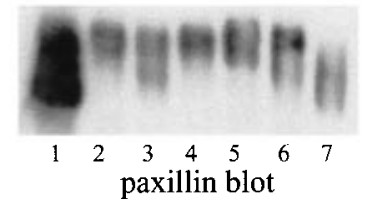

Figure 5 Characterization of phospho-specific paxillin antibodies

Cells expressing wild-type paxillin (lane 2), paxillin ${ }^{4 F}$ (lane 3), paxillin ${ }^{\mathrm{Y} 31 \mathrm{~F}}$ (lane 4), paxillin ${ }^{\mathrm{Y} 118 \mathrm{~F}}$ (lane 5), paxillin ${ }^{3531 Y}$ (lane 6) or paxillin ${ }^{35118 Y}$ (lane 7) were treated with pervanadate $(50 \mathrm{mM}$ for $30 \mathrm{~min}$ ) prior to lysis. Exogenous paxillin was immunoprecipitated using KT3. A small fraction of the immune complex, equivalent to the amount of protein from approx. $20 \mu \mathrm{g}$ of cell lysate, was loaded in each lane. Endogenous, wild-type paxillin was immunoprecipitated from $500 \mu \mathrm{g}$ of CE cell lysate and analysed in parallel (lane 1). Immune complexes were analysed by Western blotting for phosphotyrosine (ptyr; $\mathbf{A})$, a phospho-specific antibody designed to recognize phosphorylated Tyr ${ }^{31}$ of paxillin $(\mathrm{PY} 31 ; \mathbf{B})$ and a phospho-specific antibody designed to recognize phosphorylated Tyr ${ }^{118}$ of paxillin (PY118; C). The phosphotyrosine Western blot in (A) was stripped and reprobed with a paxillin polyclonal antiserum as a loading control (D).

Initially, total tyrosine phosphorylation of paxillin was examined by Western blotting with a generic phosphotyrosine antibody (Figure 5A). Comparable levels of tyrosine phosphorylation were seen on wild-type paxillin, paxillin ${ }^{\mathrm{Y} 31 \mathrm{~F}}$ and paxillin $^{\mathrm{Y} 118 \mathrm{~F}}$ (Figure 5A, lanes 2, 4 and 5). Paxillin ${ }^{3 \mathrm{~F} 31 \mathrm{Y}}$ and paxillin ${ }^{3 \mathrm{~F} 118 \mathrm{Y}}$ were also tyrosine phosphorylated, although to a reduced level relative to the other mutants (Figure 5A, lanes 6 and 7). Paxillin ${ }^{4 \mathrm{~F}}$ exhibited a very low level of phosphotyrosine, suggesting that paxillin may contain a site(s) of tyrosine phosphorylation in addition to the four mapped sites (Figure 5A, lane 3). However, since the signal is very low and phosphorylation of this site(s) can only be detected following pervanadate treatment, it is likely to be a very minor site(s) of phosphorylation. Due to the experimental set up and differential loading of endogenous and exogenously expressed paxillin, similar levels of phosphotyrosine were detected on endogenous paxillin and exogenous wild-type paxillin (Figure 5A, lanes 1 and 2). Note the decrease in relative mobility of paxillin following pervanadate treatment (Figure 5A). The antibody PY31 specifically recognized paxillin that was phosphorylated on $\mathrm{Tyr}^{31}$. The antibody reacted with endogenous paxillin and exogenously expressed wild-type paxillin, paxillin $^{\mathrm{Y} 118 \mathrm{~F}}$ and paxillin ${ }^{3 \mathrm{~F} 31 \mathrm{Y}}$ (Figure 5B, lanes 1, 2, 5 and 6). In contrast, the antibody did not react with paxillin ${ }^{4 \mathrm{~F}}$, paxillin ${ }^{\mathrm{Y} 31 \mathrm{~F}}$ or paxillin ${ }^{3 \mathrm{~F} 118 \mathrm{Y}}$ (Figure 5B, lanes 3, 4 and 7). Similarly, the antibody PY118 specifically reacted with paxillin that was phosphorylated on $\mathrm{Tyr}^{118}$. This antibody recognized endogenous paxillin and exogenously expressed wild-type paxillin, paxillin $^{\mathrm{Y} 31 \mathrm{~F}}$, and paxillin ${ }^{3 \mathrm{~F} 118 \mathrm{Y}}$ (Figure 5C, lanes 1,2, 4 and 7), but did not react with paxillin ${ }^{4 \mathrm{~F}}$, paxillin $^{\mathrm{Y} 118 \mathrm{~F}}$ or paxillin ${ }^{3 \mathrm{~F} 31 \mathrm{Y}}$ (Figure 5C, lanes 3, 5 and 6). These results demonstrate that the PY31 and PY118 antibodies specifically recognize the appropriate tyrosine-phosphorylated isomers of paxillin by Western-blot analysis.

\section{Cell adhesion-dependent tyrosine phosphorylation of residues at positions 31 and 118 of paxillin}

To explore tyrosine phosphorylation of endogenous paxillin in response to cell adhesion, CE cells were trypsinized, held in suspension and plated on to fibronectin-coated dishes. After incubation at $37^{\circ} \mathrm{C}$ for various times, cells were lysed and paxillin was immunoprecipitated and analysed by Western blotting. To again verify the specificity of the PY31 and PY118 phospho-specific antibodies in these experiments, paxillin mutants were also immunoprecipitated from pervanadate-treated cells using KT3 and analysed in parallel. When cells were taken into suspension, the phosphotyrosine content of paxillin disappeared (Figure 6A, lane 2). Tyrosine phosphorylation rapidly reappeared upon adhesion to fibronectin, although the level of phosphorylation did not reach the level of phosphorylation seen in culture even after $90 \mathrm{~min}$ on fibronectin in serum-free medium (Figure 6A, lanes 3-7). Since the level of tyrosine phosphorylation of paxillin plated on to fibronectin was reduced relative to the level of phosphorylation seen in cells growing in culture (Figure $6 \mathrm{~A}$, lane 1 versus lanes 3-7), it seemed possible that other factors affecting the cells in culture, e.g. the presence of serum factors, contributed to tyrosine phosphorylation of paxillin. To determine if serum stimulation enhanced tyrosine phosphorylation of paxillin in cells plated on fibronectin, cells that had adhered to fibronectin for 80 min were stimulated with $20 \%$ FCS for 10 min prior to lysis. Under these conditions, serum stimulation induced only a small increase in tyrosine phosphorylation of paxillin (Figure 6A, lane 8). Phosphorylation of $\mathrm{Tyr}^{31}$ and $\mathrm{Tyr}^{118}$ was examined by Western blotting using the PY31 and PY118 phospho-specific antibodies. Both residues were phosphorylated in cells growing in culture and became dephosphorylated when the cells were taken into suspension (Figures 6B and $6 \mathrm{C}$, lanes 1 and 2). Adhesion to fibronectin resulted in phosphorylation of both $\mathrm{Tyr}^{31}$ and $\mathrm{Tyr}^{118}$ (Figures $6 \mathrm{~B}$ and 6C, lanes 3-7). Stimulation of fibronectin-adhered cells with serum resulted in little change in the level of phosphorylation of these sites (Figures 6B and 6C, lanes 8). As a control, the phosphotyrosine Western blot was stripped and reprobed with a paxillin polyclonal antiserum to verify that equal levels of protein were present (Figure 6D). To investigate whether $\mathrm{Tyr}^{31}$ and $\mathrm{Tyr}^{118}$ were cell adhesion-dependent sites of phosphorylation in other cell types, a similar analysis was performed on A7r5 smooth-muscle cells. As observed in CE cells, Tyr ${ }^{31}$ and $\mathrm{Tyr}^{118}$ also became phosphorylated upon adhesion of A7r5 cells to fibronectin (results not shown). These results demonstrate that phosphorylation of $\mathrm{Tyr}^{31}$ and $\mathrm{Tyr}^{118}$ of endogenous paxillin is regulated in a cell adhesion-dependent fashion.

\section{Phosphorylation of $\mathrm{Tyr}^{31}$ and $\mathrm{Tyr}^{118}$ in response to other stimuli}

In addition to cell adhesion-dependent regulation, tyrosine phosphorylation of paxillin is induced by exposure of cells to other stimuli. For example, stimulation of smooth-muscle cells with PDGF induces tyrosine phosphorylation of paxillin, as does stimulation of the GN4 liver cell line with Ang II [28-30]. 

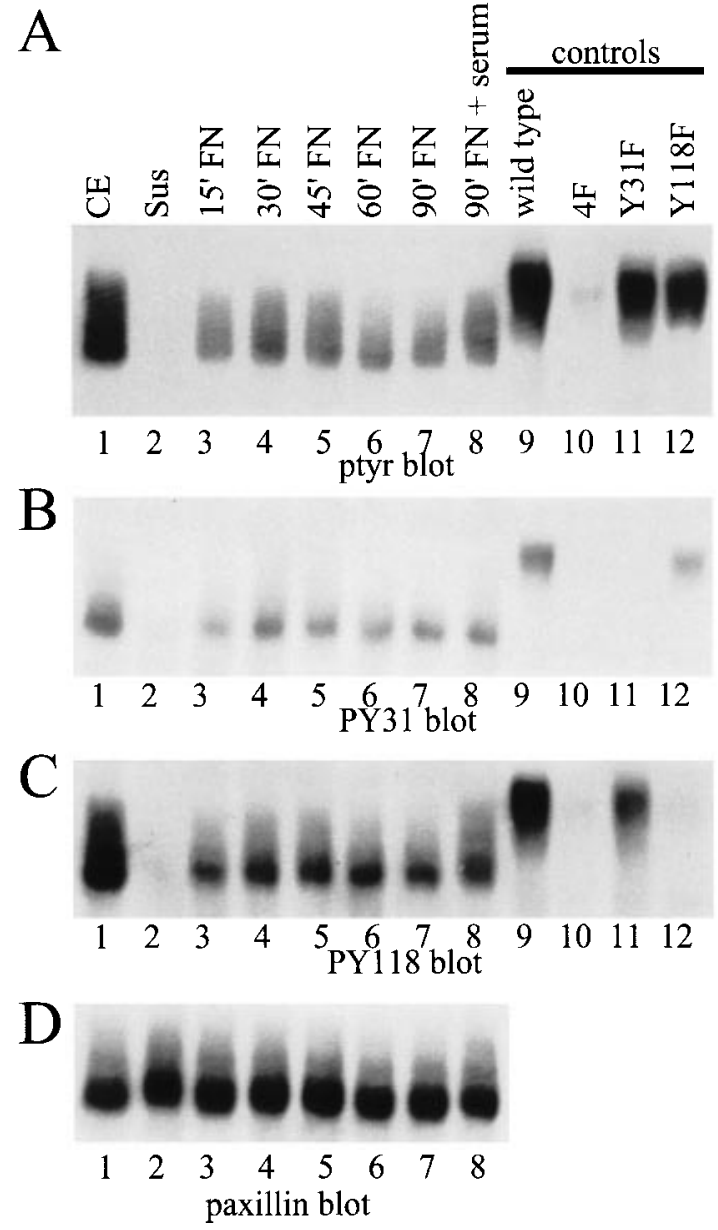

Figure 6 Analysis of cell adhesion-dependent tyrosine phosphorylation of paxillin in CE cells using phospho-specific antibodies

CE cells were held in suspension (lanes 2), or plated on to fibronectin for various times prior to lysis (lanes 3-8). One sample was plated on to fibronectin for $80 \mathrm{~min}$, then stimulated with $20 \%$ FCS for 10 min prior to lysis (lanes 8 ). As a control, CE cells growing in culture were analysed in parallel (lanes 1). Paxillin was immunoprecipitated using a polyclonal antiserum and the immune complexes analysed by Western blotting using a phosphotyrosine antibody (ptyr; A), PY31 (B) and PY118 (C). As a loading control, the phosphotyrosine Western blot in (A) was stripped and reprobed with a paxillin polyclonal antiserum (D). As controls for specificity of the phospho-specific antibodies, KT3 immune complexes from pervanadate-treated cells $(50 \mathrm{mM}$ for $30 \mathrm{~min}$ ) expressing wild-type paxillin (lane 9), paxillin ${ }^{4 \mathrm{~F}}$ (lane 10), paxillin ${ }^{\mathrm{Y31F}}$ (lane 11) or paxillin $^{\text {Y118F }}$ (lane 12) were also examined by Western blotting.

Therefore the phospho-specific paxillin antibodies were used to analyse phosphorylation of paxillin at $\mathrm{Tyr}^{31}$ and $\mathrm{Tyr}^{118}$ in response to additional stimuli. Following serum starvation, A7r5 cells were stimulated with PDGF and tyrosine phosphorylation of paxillin was analysed by immunoprecipitation and Western blotting. Serum starvation resulted in a decrease in tyrosine phosphorylation of paxillin as detected with the phosphotyrosine antibody or the phospho-specific paxillin antibodies, although very significant levels of phosphotyrosine remained (Figures 7A-5C, lanes 5). This presumably reflects the continued stimulation of paxillin phosphorylation resulting from cell adhesion to the extracellular matrix proteins. Stimulation with PDGF caused an increase in tyrosine phosphorylation of paxillin (Figures 7A-7C, lanes 6). Western blotting for paxillin verified that changes in phosphorylation did not simply reflect differential
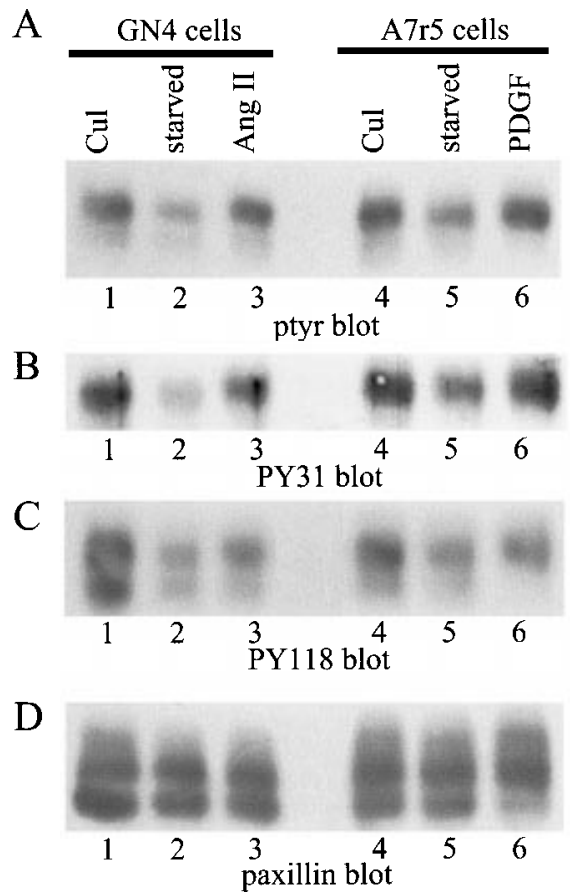

Figure 7 Analysis of paxillin phosphorylation in response to other stimuli

GN4 cells were starved for $48 \mathrm{~h}$ in serum-free RMEM (lanes 2) and stimulated with $1 \mu \mathrm{M} \mathrm{Ang}$ II for $90 \mathrm{~s}$ (lanes 3) prior to lysis. Unstarved GN4 cells were used as controls (lanes 1; Cul). A7r5 cells were starved for $48 \mathrm{~h}$ in $0.1 \%$ FCS (lanes 5) and stimulated with $2 \mathrm{ng} / \mathrm{ml} \mathrm{PDGF}$ for 10 min (lanes 6) prior to lysis. Unstarved A7r5 cells were used as controls (lanes 4; Cul). Paxillin was immunoprecipitated using a polyclonal antiserum and analysed as described in Figure 6.

recovery of protein by immunoprecipitation (Figure 7D, lanes 4-6).

Similarly, tyrosine phosphorylation of paxillin in response to Ang II treatment of GN4 cells was examined. Serum starvation reduced tyrosine phosphorylation of paxillin as detected by Western blotting for phosphotyrosine or using the phosphospecific paxillin antibodies (Figures $7 \mathrm{~A}-7 \mathrm{C}$, lanes 2). However, this treatment only caused a partial reduction in paxillin phosphorylation as observed in A $7 \mathrm{r} 5$ cells, presumably reflecting adhesion-dependent tyrosine phosphorylation in the starved cells. Stimulation with Ang II caused increased tyrosine phosphorylation of paxillin, and the results from the experiments using the phospho-specific antibodies revealed that both $\mathrm{Tyr}^{31}$ and $\mathrm{Tyr}^{118}$ become phosphorylated (Figures 7A-7C, lanes 3). The paxillin Western-blot performed as a loading control again demonstrated comparable amounts of paxillin in each lane (Figure 7D, lanes 1-3). These results demonstrate that multiple stimuli that induce tyrosine phosphorylation of paxillin, including cell adhesion, growth factors and reagents that activate G-protein-coupled receptors, promote phosphorylation of paxillin at similar tyrosine residues.

\section{DISCUSSION}

In the present study, we describe an analysis of each of the tyrosine phosphorylation sites of paxillin using a combination of phosphopeptide mapping, site-directed mutagenesis and phosphorylation site-specific antibodies. The most significant finding is that $\mathrm{Tyr}^{31}$ and $\mathrm{Tyr}^{118}$ on paxillin are the predominant sites of tyrosine phosphorylation and that diverse stimuli induce 
phosphorylation of these sites. Further, phosphorylation of $\mathrm{Tyr}^{31}$ and $\mathrm{Tyr}^{118}$ appears to be co-ordinated, since cell adhesion, PDGF and Ang II induce tyrosine phosphorylation of both sites with similar kinetics. Recently, prolonged treatment of NMuMG cells with transforming growth factor (TGF) $\beta 1$ (inducing an epithelial-mesenchymal transdifferentiation) was shown to promote tyrosine phosphorylation of paxillin, predominantly on $\mathrm{Tyr}^{31}$ and $\mathrm{Tyr}^{118}$ [31]. We also report here the identification of two additional sites of tyrosine phosphorylation in paxillin, at positions 40 and 88 . Thus each of the identified tyrosine phosphorylation sites lie near the N-terminus of the protein. However, in contrast to $\mathrm{Tyr}^{31}$ and $\mathrm{Tyr}^{118}$, these latter two sites may be minor sites of phosphorylation in vivo. Nevertheless, $\mathrm{Tyr}^{88}$ can associate with the $\mathrm{SH} 2$ domain of Csk in vitro, and thus phosphorylation of this residue might have physiological significance [11].

One interesting biochemical characteristic of paxillin is that it exhibits a heterogeneous electrophoretic mobility. Tyrosine phosphorylation is likely to retard the electrophoretic mobility of paxillin, since isomers of paxillin that are heavily tyrosine phosphorylated exhibit a reduced motility on SDS/polyacrylamide gels (Figure 5) [11]. Interestingly, mutation of $\mathrm{Tyr}^{88}$ to phenylalanine alters the electrophoretic mobility of paxillin, generating a more homogeneous species. This result suggests that tyrosine phosphorylation of the residue at position 88 of paxillin may directly alter the electrophoretic mobility of paxillin. This would be consistent with the results of phosphorylation by Src in vitro. Phosphorylation of the recombinant fragments of several paxillin substitution mutants by Src produced several phosphoisomers. In contrast, tyrosine phosphorylation of the recombinant fragment of paxillin ${ }^{\mathrm{Y} 88 \mathrm{~F}}$ did not generate the most retarded electrophoretic species. Paxillin is also extensively phosphorylated on serine $[11,19,32,33]$, and there is some evidence suggesting that phosphorylation of paxillin on serine residues by protein kinase C may retard the electrophoretic mobility of paxillin [34]. Alternatively, it is also possible that mutation of $\mathrm{Tyr}^{88}$ to phenylalanine might indirectly affect serine phosphorylation of paxillin in vivo and thus indirectly alter the electrophoretic mobility of paxillin. Further analysis is required to distinguish these possibilities.

Are there additional sites of tyrosine phosphorylation in paxillin? In addition to the two Crk-binding sites in paxillin that were previously identified as sites of phosphorylation $\left(\mathrm{Tyr}^{31}\right.$ and $\mathrm{Tyr}^{118}$ ) [10,11], there is a third tyrosine residue in paxillin that conforms to a high affinity Crk-binding site $\left(\mathrm{Tyr}^{181}\right)$ [5,9]. The analysis of the paxillin substitution mutants does not support the hypothesis that $\mathrm{Tyr}^{181}$ is a significant site of phosphorylation in CE cells. First, tyrosine phosphorylation of the recombinant fragments of paxillin by Src in vitro demonstrated that paxillin ${ }^{4 \mathrm{~F}}$, which contains $\mathrm{Tyr}^{181}$, was a very weak substrate for phosphorylation. Secondly, by phosphopeptide analysis of the paxillin substitution mutants, each of the phosphotyrosinecontaining tryptic peptides of paxillin was identified and none contained $\mathrm{Tyr}^{181}$. Finally, paxillin ${ }^{4 \mathrm{~F}}$ was expressed in $\mathrm{CE}$ cells and did not exhibit phosphotyrosine in growing cells or following adhesion to fibronectin. These observations are consistent with a published finding [35] that indirectly suggests that $\operatorname{Tyr}^{181}$ is not a site of phosphorylation. Whereas paxillin variants with substitutions for $\mathrm{Tyr}^{31}$ or $\mathrm{Tyr}^{118}$ abrogated association with the $\mathrm{SH} 2$ domain of $\mathrm{CrkL}$ in vitro, binding of a mutant with a substitution for $\mathrm{Tyr}^{181}$ to the $\mathrm{CrkL} \mathrm{SH} 2$ domain was similar to wild-type paxillin [35]. In contrast with these findings, $\operatorname{Tyr}^{181}$ was suggested to be a site of phosphorylation in NMuMG cells, although it was apparently a minor site compared with $\mathrm{Tyr}^{31}$ and $\mathrm{Tyr}^{118}$ [31]. Pervandate treatment of
CE cells occasionally induced a very low level of tyrosine phosphorylation of paxillin ${ }^{4 \mathrm{~F}}$, suggesting that an additional site(s) of phosphorylation might exist. However, such a site(s) would appear to be a very minor site of phosphorylation, and no evidence for its phosphorylation under physiological conditions was obtained. Therefore it appears that additional significant sites of tyrosine phosphorylation in paxillin are unlikely to exist in CE cells.

The main function of tyrosine phosphorylation of paxillin is to regulate the association of $\mathrm{SH} 2$ domain-containing signalling molecules with paxillin. The two predominant tyrosine phosphorylation sites, $\mathrm{Tyr}^{31}$ and $\mathrm{Tyr}^{118}$, are both found in a sequence context conforming to a high affinity $\mathrm{Crk} \mathrm{SH} 2$ domainbinding site (YXXP; where $\mathrm{X}$ is any amino acid residue), and these two residues of paxillin have been identified as Crk and CrkL binding sites [11,35,36]. However, the YXXP motif can also serve as a docking site for the $\mathrm{SH} 2$ domains of $\mathrm{Abl}$ and Nck [36], and glutathione- $S$-transferase ('GST') fusion proteins containing the $\mathrm{SH} 2$ domains of $\mathrm{Abl}$ and Nck can bind to tyrosinephosphorylated paxillin in vitro (J. M. Dunty and M. D. Schaller, unpublished work). Thus tyrosine phosphorylation of residues at positions 31 and 118 might regulate the recruitment of a number of proteins into a multifunctional signalling complex.

The observation that different physiological stimuli induce tyrosine phosphorylation of paxillin at similar tyrosine residues raises two significant questions. Are similar signalling complexes assembled following tyrosine phosphorylation of paxillin induced by different stimuli and, if so, do these complexes perform similar functions? Although different stimuli might be expected to promote the formation of similar paxillin containing signalling complexes, since they induce phosphorylation of the same tyrosine residues on paxillin, situations can be imagined where this may not be the case. For example, different stimuli might induce tyrosine phosphorylation of populations of paxillin found in distinct cellular compartments. Thus the paxillin-containing complexes that form in response to different stimuli may depend upon the subcellular localization of paxillin binding partners. Alternatively, there may be several mechanisms of regulation of assembly of specific complexes. In this scenario, only stimuli that induce paxillin phosphorylation and simultaneously signal to the paxillin binding partner would promote complex assembly. One example of a paxillin binding partner exhibiting regulated binding activity is Crk. There is a site of tyrosine phosphorylation between the two $\mathrm{SH} 3$ domains of Crk that conforms to the consensus Crk SH2 binding-site. Phosphorylation of this residue promotes intramolecular binding of the $\mathrm{SH} 2$ domain of $\mathrm{Crk}$ to this site, which inhibits the ability of Crk to interact with other binding partners [37]. Recent evidence from the literature supports the contention that tyrosine-phosphorylated paxillin may not always associate with Crk. Whereas adhesion of NBTII cells to collagen promoted the interaction of Crk with tyrosinephosphorylated paxillin [16], tyrosine-phosphorylated paxillin failed to associate with Crk or CrkL in NMuMG cells stimulated with TGF- $\beta$ [17]. These observations may be functionally significant, since tyrosine phosphorylation of paxillin appears to promote the motility of NBT-II cells and inhibit the motility of NMuMG cells [16,17]. With this in mind, the next major challenges in the elucidation of paxillin signalling will be defining the nature of signalling complexes that are assembled in response to different stimuli, the subcellular localization of these complexes and the biochemical and biological responses elicited by these complexes. Phosphorylation-defective mutants of paxillin, which have already been shown to function as dominant-negative mutants [16,17], should greatly aid the dissection of these complex signalling events. 
This project was supported by National Institutes of Health grants GM53666 and GM57943 (M.D.S.). We thank Jill Dunty, Patrick Lyons and Veronica Gabarra-Niecko for helpful comments during the course of this project and for critically reviewing this manuscript. We are also particularly indebted to Dr Tom Parsons (Department of Microbiology University of Virginia, Charlottesville, VA, U.S.A.) for support of the very early phases of this project.

\section{REFERENCES}

1 Schlaepfer, D. D., Hauck, C. R. and Sieg, D. J. (1999) Signaling through focal adhesion kinase. Prog. Biophys. Mol. Biol. 71, 435-478

2 Turner, C. E. (1998) Paxillin. Int. J. Biochem. Cell Biol. 30, 955-959

3 Glenney, J. R., Jr and Zokas, L. (1989) Novel tyrosine kinase substrates from Rous sarcoma virus-transformed cells are present in the membrane skeleton. J. Cell Biol. 108, 2401-2408

4 Birge, R. B., Fajardo, J. E., Reichman, C., Shoelson, S. E., Songyang, Z., Cantley, L. C. and Hanafusa, H. (1993) Identification and characterization of a high-affinity interaction between v-Crk and tyrosine-phosphorylated paxillin in CT10-transformed fibroblasts. Mol. Cell Biol. 13, 4648-4656

5 Salgia, R., Li, J. L., Lo, S. H., Brunkhorst, B., Kansas, G. S., Sobhany, E. S., Sun, Y., Pisick, E., Hallek, M. and Ernst, T. (1995) Molecular cloning of human paxillin, a focal adhesion protein phosphorylated by P210BCR/ABL. J. Biol. Chem. 270, 5039-5047

6 Brown, M. C., Curtis, M. S. and Turner, C. E. (1998) Paxillin LD motifs may define a new family of protein recognition domains. Nat. Struct. Biol. 5, 677-678

7 Turner, C. E., Brown, M. C., Perrotta, J. A., Riedy, M. C., Nikolopoulos, S. N., McDonald, A. R., Bagrodia, S., Thomas, S. and Leventhal, P. S. (1999) Paxillin LD4 motif binds PAK and PIX through a novel 95-kD ankyrin repeat, ARF-GAP protein: a role in cytoskeletal remodeling. J. Cell Biol. 145, 851-863

8 Weng, Z., Taylor, J. A., Turner, C. E., Brugge, J. S. and Seidel-Dugan, C. (1993) Detection of Src homology 3-binding proteins, including paxillin, in normal and v-Srctransformed Balb/c 3T3 cells. J. Biol. Chem. 268, 14956-14963

9 Turner, C. E. and Miller, J. T. (1994) Primary sequence of paxillin contains putative SH2 and SH3 domain binding motifs and multiple LIM domains: identification of a vinculin and pp125Fak-binding region. J. Cell Sci. 107, 1583-1591

10 Bellis, S. L., Miller, J. T. and Turner, C. E. (1995) Characterization of tyrosine phosphorylation of paxillin in vitro by focal adhesion kinase. J. Biol. Chem. 270 17437-17441

11 Schaller, M. D. and Parsons, J. T. (1995) pp125FAK-dependent tyrosine phosphorylation of paxillin creates a high-affinity binding site for Crk. Mol. Cell Biol. 15, 2635-2645

12 Dawid, I. B., Breen, J. J. and Toyama, R. (1998) LIM domains: multiple roles as adapters and functional modifiers in protein interactions. Trends Genet. 14, 156-162

13 Brown, M. C., Perrotta, J. A. and Turner, C. E. (1996) Identification of LIM3 as the principal determinant of paxillin focal adhesion localization and characterization of a novel motif on paxillin directing vinculin and focal adhesion kinase binding. J. Cell Biol. 135, 1109-1123

14 Richardson, A., Malik, R. K., Hildebrand, J. D. and Parsons, J. T. (1997) Inhibition of cell spreading by expression of the C-terminal domain of focal adhesion kinase (FAK) is rescued by coexpression of Src or catalytically inactive FAK: a role for paxillin tyrosine phosphorylation. Mol. Cell Biol. 17, 6906-6914

15 Richardson, A. and Parsons, T. (1996) A mechanism for regulation of the adhesionassociated protein tyrosine kinase pp125FAK. Nature (London) 380, 538-540

16 Petit, V., Boyer, B., Lentz, D., Turner, C. E., Thiery, J. P. and Valles, A. M. (2000) Phosphorylation of tyrosine residues 31 and 118 on paxillin regulates cell migration through an association with CRK in NBT-II cells. J. Cell Biol. 148, 957-970

17 Yano, H., Uchida, H., Iwasaki, T., Mukai, M., Akedo, H., Nakamura, K., Hashimoto, S. and Sabe, H. (2000) Paxillin alpha and crk-associated substrate exert opposing effects on cell migration and contact inhibition of growth through tyrosine phosphorylation. Proc. Natl. Acad. Sci. U.S.A. 97, 9076-9081
18 Liu, S., Thomas, S. M., Woodside, D. G., Rose, D. M., Kiosses, W. B., Pfaff, M. and Ginsberg, M. H. (1999) Binding of paxillin to alpha4 integrins modifies integrindependent biological responses. Nature (London) 402, 676-681

19 Brown, M. C., Perrotta, J. A. and Turner, C. E. (1998) Serine and threonine phosphorylation of the paxillin LIM domains regulates paxillin focal adhesion localization and cell adhesion to fibronectin. Mol. Biol. Cell 9, 1803-1816

20 Turner, C. E. (1994) Paxillin: a cytoskeletal target for tyrosine kinases. BioEssays 16, $47-52$

21 Sabe, H., Hata, A., Okada, M., Nakagawa, H. and Hanafusa, H. (1994) Analysis of the binding of the Src homology 2 domain of Csk to tyrosine-phosphorylated proteins in the suppression and mitotic activation of c-Src. Proc. Natl. Acad. Sci. U.S.A. 91, 3984-3988

22 Bergman, M., Joukov, V., Virtanen, I. and Alitalo, K. (1995) Overexpressed Csk tyrosine kinase is localized in focal adhesions, causes reorganization of alpha $\mathrm{V}$ beta 5 integrin, and interferes with HeLa cell spreading. Mol. Cell Biol. 15, 711-722

23 Reynolds, A. B., Roesel, D. J., Kanner, S. B. and Parsons, J. T. (1989) Transformation-specific tyrosine phosphorylation of a novel cellular protein in chicken cells expressing oncogenic variants of the avian cellular src gene. Mol. Cell Biol. $\mathbf{9}$, 629-638

24 Thomas, J. W., Cooley, M. A., Broome, J. M., Salgia, R., Griffin, J. D., Lombardo, C. R. and Schaller, M. D. (1999) The role of focal adhesion kinase binding in the regulation of tyrosine phosphorylation of paxillin. J. Biol. Chem. 274, 36684-36692

25 Schaller, M. D. and Sasaki, T. (1997) Differential signaling by the focal adhesion kinase and cell adhesion kinase beta. J. Biol. Chem. 272, 25319-25325

26 Shen, Y. and Schaller, M. D. (1999) Focal adhesion targeting: the critical determinant of FAK regulation and substrate phosphorylation. Mol. Biol. Cell 10, 2507-2518

27 Laemmli, U. K. (1970) Cleavage of structural proteins during the assembly of the head of bacteriophage T4. Nature (London) 227, 680-685

28 Brinson, A. E., Harding, T., Diliberto, P. A., He, Y., Li, X., Hunter, D., Herman, B., Earp, H. S. and Graves, L. M. (1998) Regulation of a calcium-dependent tyrosine kinase in vascular smooth muscle cells by angiotensin II and platelet-derived growth factor. Dependence on calcium and the actin cytoskeleton. J. Biol. Chem. 273, $1711-1718$

$29 \mathrm{Li}$, X. and Earp, H. S. (1997) Paxillin is tyrosine-phosphorylated by and preferentially associates with the calcium-depedent tyrosine kinase in rat liver epithelial cells. J. Biol. Chem. 272, 14341-14348

30 Abedi, H., Dawes, K. E. and Zachary, I. (1995) Differential effects of platelet-derived growth factor BB on p125 focal adhesion kinase and paxillin tyrosine phosphorylation and on cell migration in rabbit aortic vascular smooth muscle cells and Swiss 3T3 fibroblasts. J. Biol. Chem. 270, 11367-11376

31 Nakamura, K., Yano, H., Uchida, H., Hashimoto, S., Schaefer, E. and Sabe, H. (2000) Tyrosine phosphorylation of paxillin alpha is involved in temporospatial regulation of paxillin-containing focal adhesion formation and F-actin organization in motile cells. J. Biol. Chem. 275, 27155-27164

32 De Nichilo, M. 0. and Yamada, K. M. (1996) Integrin alpha v beta 5-dependent serine phosphorylation of paxillin in cultured human macrophages adherent to vitronectin. J. Biol. Chem. 271, 11016-11022

33 Bellis, S. L., Perrotta, J. A., Curtis, M. S. and Turner, C. E. (1997) Adhesion of fibroblasts to fibronectin stimulates both serine and tyrosine phosphorylation of paxillin. Biochem. J. 325, 375-381

34 Zachary, I., Sinnett-Smith, J., Turner, C. E. and Rozengurt, E. (1993) Bombesin, vasopressin, and endothelin rapidly stimulate tyrosine phosphorylation of the focal adhesion-associated protein paxillin in Swiss 3T3 cells. J. Biol. Chem. 268, 22060-22065

35 Salgia, R., Uemura, N., Okuda, K., Li, J. L., Pisick, E., Sattler, M., de Jong, R. Druker, B., Heisterkamp, N. and Chen, L. B. (1995) CRKL links p210BCR/ABL with paxillin in chronic myelogenous leukemia cells. J. Biol. Chem. 270, 29145-29150

36 Songyang, Z., Shoelson, S. E., Chaudhuri, M., Gish, G., Pawson, T., Haser, W. G., King, F., Roberts, T., Ratnofsky, S. and Lechleider, R. J. (1993) SH2 domains recognize specific phosphopeptide sequences. Cell (Cambridge, Mass.) 72, 767-778

37 Feller, S. M., Knudsen, B. and Hanafusa, H. (1994) c-Abl kinase regulates the protein binding activity of c-Crk. EMBO J. 13, 2341-2351

Received 4 June 2001/11 July 2001; accepted 29 August 2001 